\title{
SATISFAÇÃO DE ESTUDANTES EM ADMINISTRAÇÃO DE JOINVILLE/SC
}

\author{
SATISFACTION OF STUDENTS IN MANAGEMENT OF JOINVILLE/SC
}

\author{
Emerson Wagner Mainardes \\ Universidade da Beira Interior/UBI - Covilhã/Portugal \\ Maria José Carvalho de Souza Domingues \\ Universidade Regional de Blumenau/FURB
}

\section{RESUMO}

Este estudo objetivou avaliar a satisfação dos atuais alunos das instituições de ensino superior (IES) de Joinville, SC, com os aspectos referentes a instituição de ensino onde realizam a graduação em administração. Inicialmente, buscou-se estudos que tratam da satisfação de estudantes, encontrandose 18 atributos que medem a satisfação dos alunos com sua IES. Após, realizou-se uma pesquisa quantitativa-descritiva junto aos alunos formandos em duas das cinco IES que oferecem o curso de administração em Joinville, SC, onde aplicou-se um questionário estruturado junto a 283 formandos. Primeiro, caracterizou-se estes formandos. Depois, identificou-se o desempenho dos atributos referentes à satisfação dos alunos nos aspectos ligados a sua instituição. Encontrou-se também os atributos que mais contribuem para a satisfação dos alunos. Os alunos mostraram-se satisfeitos, e ressaltaram que a imagem da IES entre os alunos é o principal fator na formação da satisfação dos estudantes, bem como o ambiente na IES é o mínimo que um aluno espera de sua instituição.

Palavras-chave: Satisfação de alunos. Instituição de ensino superior. Curso de administração.

\begin{abstract}
This study aimed to evaluate the satisfaction of current students in higher education institutions (HEIs) from Joinville, SC, with aspects related to the educational institution where you hold a degree in administration. Initially, we attempted to studies dealing with the satisfaction of students and are 18 items that measure students' satisfaction with their HEIs. After, there was a quantitative-descriptive research with students in two of the five HEIs offering the course of management in Joinville, SC, applying a structured questionnaire to 283 students. First characterized these graduates. Then it was identified performance attributes relating to student satisfaction in the aspects related to their institution. Also found the attributes that the most contribute to student satisfaction. Students were satisfied, and stressed that the image of the HEI among students is the main factor in the formation of student satisfaction and the environment in the IES is the minimum that a student waiting for your institution.
\end{abstract}

Keywords: Students satisfaction. Higher education institutions. Management course. 


\section{INTRODUÇÃO}

Em um mundo em constante transformação, os profissionais do mercado de trabalho necessitam estar sempre se aperfeiçoando e se capacitando. Capacitação de profissionais do mercado, em muitos casos, se busca em instituições de ensino superior (IES). Reinert e Reinert (2005) evidenciaram que este cenário no Brasil permitiu o crescimento do setor educacional nos ensinos fundamental, médio e superior. Porém, é neste último, no nível superior em particular que o ensino brasileiro ganhou espaço considerável. 0 crescimento do número de instituições privadas foi recorde, nascendo, em média, mais de um estabelecimento particular por dia. Entre os cursos oferecidos pelas IES, a graduação em administração cresceu, significativamente. Silva et al (2005) constataram que a ampliação do ensino superior no Brasil foi nitidamente visível, e que houve um maior crescimento nos cursos de graduação em administração.

Esta situação, entre outros fatores, foi proporcionada pela Lei de Diretrizes e Bases (LDB), Lei 9.394 de 1996 (PLANALTO, 2007), que tornou o ambiente educacional favorável ao aumento deste tipo de organização, principalmente as IES privadas. Neste contexto houve, assim, natural aumento de competitividade entre estas instituições. Desta forma, segundo Walter, Tontini e Domingues (2005, p. 1), "o mercado educacional aproxima-se cada vez mais de um mercado onde a qualidade dos serviços e a satisfação dos clientes são fundamentais para sobrevivência das IES". Complementando este cenário, Navarro, Iglesias e Torres (2005), em estudo internacional, constataram uma diminuição no acesso as IES de estudantes recém formados no ensino médio. Conforme estes mesmos autores, têm-se cada vez alunos mais maduros, já profissionais do mercado, que buscam se qualificar, com necessidades e motivações diferentes dos estudantes tradicionais, e que exigem uma educação diferente, mais voltada a conhecimentos úteis ao trabalho.

As IES da atualidade estão tendo que se interessar não só pelo que a sociedade solicita, em termos de competência dos diplomados, mas também pelo que os estudantes sentem sobre a experiência educacional que tem, vão ter ou tiveram (ABDULLAH, 2006). Seeman e O'Hara (2006) afirmam que neste ambiente, as IES garantem uma vantagem competitiva, com o aumento de habilidades em atrair, reter e atender seus consumidores. O Brasil acompanha esta tendência. Cada vez mais, a competição entre IES nacionais, principalmente em cursos de graduação em administração, leva as instituições a buscar formas de atrair e reter estudantes.

Esta realidade nacional apresenta-se com força, principalmente em regiões onde a necessidade de formação de administradores é constante. Um exemplo é Joinville, Santa Catarina. Esta é a maior cidade do estado, apesar de não ser a capital. Tem uma quantidade elevada de empresas privadas, tanto indústrias, quanto comércios e prestadoras de serviços. É um pólo industrial que concentra grandes organizações, sendo também uma cidade com forte vocação empreendedora. São mais de 50 mil empresas, sendo que cada uma delas precisa de, pelo menos, um administrador. Portanto, esta necessidade de formação em administração levou a uma proliferação de cursos de graduação nesta área.

Na cidade de Joinville, SC, existem, de acordo com o Instituto Nacional de Estudos e Pesquisas Educacionais (INEP, 2007), cinco IES particulares, que oferecem doze diferentes cursos de graduação em administração. Apesar do mercado de trabalho apresentar uma demanda constante por novos administradores, as IES tem cada vez mais dificuldades para atrair novos alunos, pois são oferecidas quase duas mil vagas anuais, e isto significa atrair cerca de dois mil indivíduos todos os anos para as IES somente para cursos de administração, não sendo considerados os demais inúmeros cursos superiores oferecidos por estas e por outras IES da 
região, tornando a satisfação de alunos uma estratégia de gestão fundamental para as IES locais.

É sob esta perspectiva que se realizou este estudo. Considerando-se as necessidades do mercado de trabalho e a realidade competitiva do meio educacional, avaliar a satisfação dos atuais alunos das IES de Joinville, SC, com os aspectos gerais da instituição onde cursam da graduação em administração é o grande objetivo desta pesquisa.

Assim sendo, a questão de pesquisa na qual se baseia este estudo é a seguinte:

Quais são os fatores da instituição que mais satisfazem os alunos da graduação em administração em IES privadas de Joinville, SC?

Para responder a esta pergunta, primeiro caracterizou-se o atual estudante da graduação em administração nas IES privadas de Joinville, SC. Em seguida analisou-se a satisfação destes alunos quanto aos atributos gerais da IES, bem como identificou-se os principais atributos relacionados a instituição de ensino na formação da satisfação de alunos com seus cursos de administração e suas IES.

Este estudo pretendeu contribuir com os gestores das IES no sentido de que a satisfação dos alunos é fundamental para a atração de novos alunos e retenção dos atuais estudantes. Satisfação leva a lealdade, atributo relevante para a sobrevivência das atuais organizações (ALVES, 2003). Considerando a competitividade do mercado educacional brasileiro na atualidade, justifica-se este estudo ao apontar fatores de satisfação e insatisfação de alunos em requisitos notadamente importantes, os fatores gerais da IES (ambiente, atendimento dos funcionários da IES, biblioteca, serviço educacional, entre outros). Estende se a contribuição deste estudo para a academia, ao diagnosticar o desempenho das IES atuais no sentido de atender as necessidades dos alunos, uma das principais missões das universidades. Os atributos mencionados neste estudo podem dar origem a outros estudos semelhantes nas mais variadas regiões do planeta.

O estudo é apresentado em quatro partes. Inicia com a revisão teórica dos conceitos de satisfação estudantil e a identificação de atributos gerais de satisfação com as IES. Em seguida, apresenta-se a metodologia aplicada a pesquisa realizada. Na seqüência faz-se a análise dos dados. Finaliza-se o estudo com as conclusões e recomendações.

\section{SATISFAÇÃO DE ESTUDANTES E ASPECTOS LIGADOS AO MERCADO DE TRABALHO}

Para tratar de satisfação de clientes, nesse caso, de estudantes, precisa-se entender que este tema é o foco de organizações orientadas para o mercado. Rowley (2003) defende que a orientação para o mercado é uma filosofia que coloca os clientes e as necessidades deles no coração do que a organização faz. Para agir de um modo eficiente, as organizações definem grupos de clientes e buscam satisfazer às necessidades desses grupos.

Partindo desse princípio, considera-se que satisfação estudantil é uma resposta afetiva, por um determinado tempo, e é o resultado da avaliação dos serviços pedagógicos e do apoio aos estudos oferecidos ao estudante pela universidade (PALACIO; MENESES; PÉREZ, 2002). Para saber se o que está sendo oferecido atende às necessidades desse novo público, pode-se medir os níveis de satisfação alcançados por esses estudantes (NAVARRO; IGLESIAS; TORRES, 2005). A satisfação é determinada por diversos fatores, como expectativas dos estudantes antes de entrar na universidade, as idéias que os levaram a determinada universidade, e as 
variáveis do componente cognitivo de satisfação.

Alves (2003) define satisfação do estudante como sendo o resultado global obtido com a experiência educacional em todas as suas vertentes, podendo ser apenas um sentimento detido pelo estudante ou um conhecimento mais racional. A satisfação de estudantes tende a ser influenciada por duas grandes características do desempenho da IES: o intelectual (envolvimento do aluno com os docentes, administradores e outros estudantes, e ensino efetivo), proporcionado por docentes e estudantes, e pelo grau de preparação do estudante para sua carreira profissional. A satisfação dos estudantes com o programa educacional depende, também, do sucesso do programa em satisfazer as necessidades dos estudantes.

Essa mesma autora confirma que a (in) satisfação de alunos resulta:

- Da comparação que o eles fazem da própria situação com a de outros estudantes em outras universidades (imagem);

- Da análise do desempenho da universidade, na prestação do serviço educacional;

- Da comparação do desempenho da universidade com as expectativas iniciais;

- De um sentimento geral a respeito da universidade (misto de conhecimento e emoção despertada por diversos processos, desconfirmação das expectativas e o da eqüidade/comparação).

A satisfação com a experiência educacional, para um aluno do ensino superior, passa não só pela forma como a universidade presta o serviço, mas também pela percepção dele sobre o resultado final desse mesmo serviço. À medida que os alunos avançam nos estudos, as percepções de valor e expectativas diminuem. 0 mesmo acontece com a satisfação.

No estudo realizado por Olavarrieta, Oliva e Manzur (2003), são referenciados aspectos que correspondem à utilidade de alguns cursos no trabalho e as principais forças e fraquezas da educação recebida. Os resultados dessa pesquisa indicam, na ótica do aluno, que a maioria dos cursos oferecidos por universidades são úteis para o trabalho e que os alunos estão satisfeitos com o tipo de ensino recebido. Entretanto, os autores aconselham que o ensino deveria ser mais prático, que o uso da informática deveria estar orientada à geração de habilidades nos alunos, o que levaria a um melhor rendimento no trabalho, e que houvesse melhoria nas áreas relacionadas com a comunicação, tanto oral como escrita.

Lanzer (2004) comenta que a IES que busca ser reconhecida como uma instituição de referência, percebida pela qualidade de suas ações e resultados, tem na satisfação de seus clientes internos (alunos) e externos (sociedade) um dos seus principais valores. Para isso, na gestão da IES, permanecem como direções estratégicas a gestão integrada visando à qualidade e aos resultados; colaboradores competentes, comprometidos, inovadores e satisfeitos; e ensino, pesquisa e extensão com qualidade e resultados conhecidos. Para desenvolver o sistema de produção e definir os padrões de qualidade, o foco das universidades tem que estar na satisfação de seus estudantes. 0 não atendimento a esse quesito implica em altos índices de inadimplência e evasão.

Em Colauto et al. (2005), destaca-se que as IES privadas necessitam avaliar os fatores críticos da instituição, na percepção dos acadêmicos, no momento da fixação de preços de mensalidades, bem como monitorar as variáveis estratégicas determinantes no processo de satisfação de seus clientes. Na pesquisa realizada pelos autores, os resultados mostram que as 
principais variáveis de valor total para o aluno são a qualificação do corpo docente, qualidade do curso, retorno dos investimentos e adequação dos recursos físicos. As demais variáveis (número de alunos por sala, serviços administrativos e suporte técnico, tradição da IES, promoção de eventos) mostram-se menos importantes.

De acordo com Walter, Tontini e Domingues (2005, p. 1-2), em uma IES

a satisfação dos usuários envolve dois aspectos: de um lado, a percepção da sociedade que recebe o "produto-aluno", que dependendo do seu desempenho técnico e humano propaga uma imagem positiva da IES, desencadeando novas demandas; de outro lado, os alunos, que podem ter uma percepção de momento ou de futuro em relação aos serviços que recebem, tendo um nível de satisfação em relação a diversos atributos internos da IES, tais como coordenação, professores, exigência dos estudos, atendimento da secretaria, infra-estrutura, biblioteca e outros. Esta satisfação também influencia na demanda, pois os alunos comunicam-se com colegas e a sociedade em geral.

Alunos satisfeitos com os serviços internos da IES e com os cursos que ela oferece influenciam positivamente na percepção que a sociedade e futuros alunos têm a seu respeito, aumentando a demanda. Já uma percepção negativa terá efeito contrário. Assim, identificar como os diferentes atributos da IES e seus cursos afetam a satisfação dos alunos e qual o nível atual de satisfação, torna-se crítico para o gerenciamento eficaz da IES.

Para Navarro, Iglesias e Torres (2005), o conceito de satisfação é uma variável de administração essencial para se alcançar os objetivos estratégicos de instituições universitárias. Esses autores oferecem uma série de fatores que, se agradarem aos estudantes, podem propiciar a satisfação deles pela IES e a lealdade à instituição. Porém um número alto de fatores cria dificuldades ao se tentar desenvolver uma administração que abranja todos esses fatores.

Uma administração desse tipo seria facilitada com uma diminuição no número de fatores a serem controlados. Os autores propõem, como solução, os seguintes agrupamentos: instalações, equipe pedagógica, métodos pedagógicos, ambiente, administração de curso e serviços de apoio. Segundo os autores, esses fatores contribuem para a satisfação de estudantes, na busca da lealdade deles (NAVARRO; IGLESIAS; TORRES, 2005).

Considerando-se os fatores citados, pode-se identificar que os aspectos que determinam a satisfação de estudantes são os que estão relacionados diretamente ao serviço essencial, ou seja, a métodos pedagógicos, à administração de curso e à equipe pedagógica.

Em suma, tomando por base pesquisas anteriormente realizadas que abordaram o assunto, surgiram 18 atributos gerais de satisfação de alunos com sua IES (quadro 1). Estes atributos foram testados na pesquisa aqui apresentada, objetivando-se identificar quais destes atributos apresentam melhor desempenho nas IES que o oferecem a graduação em administração em Joinville, SC, bem como procurou-se determinar quais são, entre estes atributos testados, os que mais contribuem na formação da satisfação dos estudantes com sua instituição de ensino. 
Quadro 1: Atributos de satisfação de alunos relacionados a IES

\begin{tabular}{|c|c|}
\hline \multicolumn{2}{|c|}{ ATRIBUTOS DA IES NA SATISFAÇÃO DE ALUNOS } \\
\hline ATRIBUTOS IDENTIFICADOS & AUTOR (ES) \\
\hline $\begin{array}{l}\text { Ambiente universitário, clima no campus, vida no } \\
\text { campus }\end{array}$ & $\begin{array}{l}\text { Silva (2000); Walther (2000); Alves (2003); Navarro, } \\
\text { Iglesias e Torres (2005) }\end{array}$ \\
\hline $\begin{array}{l}\text { Atendimento na secretaria e } \\
\text { serviços de apoio no campus }\end{array}$ & $\begin{array}{l}\text { Olavarrieta, Oliva e Manzur (2003); Walter, Tontini e } \\
\text { Domingues (2005); Navarro, Iglesias e Torres (2005) }\end{array}$ \\
\hline $\begin{array}{l}\text { Biblioteca, livraria universitária, existência de } \\
\text { bibliografia básica, atendimento dos bibliotecários } \\
\text { e facilidade de acesso a bibliografias e } \\
\text { documentações }\end{array}$ & $\begin{array}{l}\text { Alves e Raposo (1999); Olavarrieta, Oliva e Manzur (2003); } \\
\text { Walter, Tontini e Domingues (2005); Navarro, Iglesias e } \\
\text { Torres (2005) }\end{array}$ \\
\hline Construção de relações e impressões com clientes & Rowley (2003); Olavarrieta, Oliva e Manzur (2003) \\
\hline $\begin{array}{l}\text { Contribuição do pessoal que entra em contato } \\
\text { direto com os clientes e com o público }\end{array}$ & Rowley (2003); Lanzer (2004) \\
\hline $\begin{array}{l}\text { Coordenação e organização dos cursos; } \\
\text { administração dos cursos, competência dos } \\
\text { administradores e coordenadores }\end{array}$ & $\begin{array}{l}\text { Astin (2001); Alves (2003); Olavarrieta, Oliva e Manzur } \\
\text { (2003); Walter, Tontini e Domingues (2005); Navarro, } \\
\text { Iglesias e Torres (2005); Colauto et al. (2005) }\end{array}$ \\
\hline $\begin{array}{l}\text { Cortesia, amabilidade, competência dos recursos } \\
\text { humanos da IES }\end{array}$ & $\begin{array}{l}\text { Franklin e Shemwell (1995); Alves (2003); Olavarrieta, } \\
\text { Oliva e Manzur (2003); Walter, Tontini e Domingues (2005) }\end{array}$ \\
\hline Desenvolvimento de ofertas apropriadas & Rowley (2003); Olavarrieta, Oliva e Manzur (2003) \\
\hline $\begin{array}{l}\text { Disponibilidade de apoio social ao aluno e } \\
\text { prestação de serviços sociais }\end{array}$ & $\begin{array}{l}\text { Alves e Raposo (1999); Alves (2003); Walter, Tontini e } \\
\text { Domingues (2005) }\end{array}$ \\
\hline $\begin{array}{l}\text { Identificação das necessidades dos clientes e foco } \\
\text { em produtos e serviços para compra, consumo }\end{array}$ & $\begin{array}{l}\text { Franklin e Shemwell (1995); Palácio, Meneses e Pérez } \\
\text { (2002); Alves (2003); Mavondo, Chimhanzi e Stewart } \\
\text { (2005) }\end{array}$ \\
\hline Imagem da IES & Alves (2003); Navarro, Iglesias e Torres (2005) \\
\hline $\begin{array}{l}\text { Inovação em produtos e serviços, processos, } \\
\text { modos de negociar e administração da IES }\end{array}$ & $\begin{array}{l}\text { Walther (2000); Alves (2003); Mavondo, Chimhanzi e } \\
\text { Stewart (2005) }\end{array}$ \\
\hline $\begin{array}{l}\text { Ligações da IES com o exterior, intercâmbios } \\
\text { com o estrangeiro. }\end{array}$ & $\begin{array}{l}\text { Alves (1998); Alves e Raposo (1999); Alves (2003); Walter, } \\
\text { Tontini e Domingues (2005) }\end{array}$ \\
\hline $\begin{array}{l}\text { Preço e condições de pagamento, e serviços } \\
\text { financeiros. }\end{array}$ & $\begin{array}{l}\text { Hampton (1993); Alves (2003); Navarro, Iglesias e Torres } \\
\text { (2005); Colauto et al. (2005) }\end{array}$ \\
\hline Qualidade percebida de serviços & $\begin{array}{l}\text { Alves (2003); Olavarrieta, Oliva e Manzur (2003); Lanzer } \\
\text { (2004); Gastal e Luce (2005); Santos e Fernandes (2005) }\end{array}$ \\
\hline $\begin{array}{l}\text { Sentimentos de confiança do consumidor } \\
\text { na IES e seus funcionários }\end{array}$ & Silva (2000); Santos e Fernandes (2005) \\
\hline Solução e gerenciamento de reclamações & $\begin{array}{l}\text { Alves e Raposo (1999); Silva (2000); Alves (2003); Santos e } \\
\text { Fernandes (2005) }\end{array}$ \\
\hline $\begin{array}{l}\text { Variáveis relacionadas com a existência de } \\
\text { atividades desportivas, culturais e associações de } \\
\text { alunos. }\end{array}$ & $\begin{array}{l}\text { Alves e Raposo (1999); Olavarrieta, Oliva e Manzur (2003); } \\
\text { Walter, Tontini e Domingues (2005) }\end{array}$ \\
\hline
\end{tabular}




\section{MÉTODO DE PESQUISA}

Neste estudo, realizou-se uma pesquisa quantitativa descritiva transversal, por meio de levantamento de dados primários, com a aplicação de questionário com perguntas predominantemente fechadas (HAIR et al, 2005).

Na pesquisa realizada, foram consideradas todas as IES de Joinville, SC, que oferecem cursos de graduação em administração. Segundo dados do INEP (2007), são cinco IES que oferecem, ao total, doze cursos de graduação em administração. São elas: Universidade da Região de Joinville (UNIVILLE); Faculdade Cenecista de Joinville (FCJ); Instituto de Ensino Superior de Joinville (IESVILLE); Instituto Superior de Tecnologia (IST); Instituto de Ensino Santo Antônio (INESA).

Para identificar nestas IES os atributos de melhor desempenho na satisfação dos estudantes com seu curso e sua IES em aspectos relacionados ao mercado de trabalho, optouse pelos alunos formandos no curso de graduação em administração (respondentes-chave), pois considera-se serem os mais críticos quanto ao serviço educacional que receberam (OLAVARRIETA; OLIVA; MANZUR, 2003). Esta escolha não oportunizou a participação dos alunos que estudam nas IES IST e INESA, uma vez que os cursos de graduação em administração nestas duas IES são recentes, e ainda estão nos primeiros anos ou semestres, não possuindo alunos formandos. Foram assim selecionados, como respondentes-chave, os alunos formandos em administração da UNIVILLE, FCJ e IESVILLE.

De acordo com as informações obtidas junto às Secretarias das IES que participaram do estudo, identificou-se 616 alunos no último ano ou semestre de 2007. Utilizando a fórmula de Barbetta (2003, p. 60) para determinar o cálculo da amostra estratificada proporcional, esta ficou em 242 alunos formandos, nas três IES consideradas para o estudo. Ou seja, para ser válida, esta pesquisa deveria entrevistar no mínimo 242 alunos (erro de 5\%). Se alcançasse mais estudantes, o erro amostral reduziria-se. Estabeleceu-se então a aplicação de 350 questionários, possivelmente garantindo, no mínimo, 242 instrumentos devidamente respondidos.

Este estudo realizou a coleta de dados a partir da aplicação de um questionário estruturado não disfarçado, com perguntas predominantemente fechadas, e que foi baseado no estudo de Mainardes (2007). 0 questionário foi composto de duas partes. Na primeira parte, buscou-se caracterizar o aluno que respondeu a pesquisa, por meio de uma pergunta aberta (idade) e seis perguntas fechadas (gênero, estado civil, número de filhos, local de trabalho, função profissional e área de atuação profissional). A segunda parte do questionário procurou identificar o desempenho dos atributos na avaliação da satisfação dos alunos com sua IES especificamente em aspectos relacionados a própria instituição, excluindo-se fatores relacionados ao curso e ao mercado de trabalho. Os questionários em questão foram construídos conforme os passos descritos a seguir:

- Passo 1 - Levantamento de Atributos: Revisão bibliográfica (quadro 1);

- Passo 2 - Identificação dos Atributos: Entre os inúmeros atributos de medem a satisfação de estudantes, encontrou-se 18 ligados a IES de forma geral;

- Passo 3 - Estratégias: Com os grupos de atributos formatados, partiu-se para odesenvolvimento das estratégias (quadro 2). 
Quadro 2: Estratégias de mensuração dos dados

\section{ESTRATÉGIAS DE MENSURAÇÃO DOS DADOS}

Estratégia 1 - Medição individual do desempenho de cada atributo: aplicou-se um escalograma de diferencial
semântico para cada atributo com escala de 1 a 7 (de pior para melhor desempenho);
Estratégia 2 - Mensuração do desempenho geral: ao final do grupo de atributos, foi solicitado ao respondente
que fizesse uma avaliação geral de todos os atributos citados, nos mesmos moldes da medida individual, ou seja,
em um escalograma de diferencial semântico, com escala variando de 1 a 7 (de pior para melhor desempenho);
foi uma pergunta que mediu a satisfação geral dos alunos com sua IES no que se refere aos aspectos
exclusivamente a instituição de ensino.

Os meses de fevereiro e março de 2007 foram escolhidos para a aplicação da pesquisa em virtude de ser o momento onde há maior presença de estudantes em salas de aulas (início das aulas). Os autores deste estudo prontificaram-se a estarem presentes pessoalmente em cada sala de aula para a aplicação da pesquisa. Isto aconteceu nas pesquisas realizadas nas IES UNIVILLE e FCJ. A IES IESVILLE não autorizou a realização da pesquisa em suas dependências.

Foram distribuídos 350 questionários nas duas IES. Destes, 298 foram devolvidos preenchidos. Após a análise dos pesquisadores, 283 questionários foram validados, número superior aos 242 necessários para validação estatística da pesquisa (erro de 5\%). 0 erro amostral foi recalculado e ficou em 4,3\%.

No processo de análise dos dados, primeiramente, foram realizadas as análises descritivas básicas de cada variável, possibilitando-se chegar as primeiras conclusões. Em um segundo momento, foi utilizada a análise multivariada de regressão múltipla linear. Esta técnica de análise multivariada permitiu realizar a melhor análise possível dos dados coletados e atingir aos objetivos desta pesquisa, que era identificar os atributos chave da instituição de ensino que contribuem para a satisfação dos estudantes da gradução em administração das IES privadas de Joinville, SC.

Para classificar os atributos desta pesquisa, utilizou-se o método proposto por Tontini e Silveira (2005). Os autores demonstraram uma forma de avaliar o desempenho, utilizando os resultados do desempenho declarado pelos respondentes e o desempenho calculado estatisticamente via regressão linear múltipla (nota geral como variável dependente e notas dadas aos atributos como variáveis independentes). Atributos que recebem altas notas pelos dois métodos são considerados "chave". Similarmente, atributos que recebem baixas notas nos dois métodos são considerados secundários. Aqueles que recebem notas altas no método declarado e notas baixas no método estatístico são considerados "básicos". Já os que recebem notas baixas no método declarado e notas altas no método estatístico são considerados como "amplificadores".

\section{ANÁLISE DOS DADOS}

Inicialmente analisou-se as características dos formandos em administração das IES de Joinville, SC. Em um segundo momento, fez-se a análise da satisfação dos alunos quanto a sua IES no que se refere aos fatores ligados exclusivamente a instituição de ensino. Identificou-se os atributos de melhor e pior desempenho e em seguida os atributos que mais contribuem para formar a satisfação dos alunos quanto a uma IES, quando se trata de aspectos próprios da instituição.

\section{CARACTERIZAÇÃO DOS ALUNOS FORMANDOS EM ADMINISTRAÇÃO EM JOINVILLE,SC}


A primeira parte da pesquisa buscou caracterizar os alunos formandos dos cursos de graduação em administração das IES privadas de Joinville/SC.

No início da análise dos dados coletados junto aos alunos formandos em administração de duas IES de Joinville/SC, foram caracterizados os respondentes. Essa fase inicial disponibiliza o perfil do aluno que inicia e realiza completamente o curso de administração, representando, assim, um dado relevante para os gestores das IES. Dos 283 alunos entrevistados, 37\% pertencem à UNIVILLE e 63\% à FCJ. Conforme já citado, as IES INESA e IST têm cursos muito recentes e ainda não possuem alunos formandos. Quanto à IESVILLE, conforme comentado, esta não permitiu a realização da pesquisa junto a seus alunos formandos. A caracterização desses alunos é visualizada por meio de diferentes aspectos:

- a idade média dos respondentes é de 26 anos (mediana - 25 anos; moda - 21 anos - 41 casos), sendo que o mais jovem conta com 20 anos e o mais maduro, com 45 anos;

- predominância do gênero feminino, com 58\% dos alunos que estão concluindo a graduação em Administração, contra 42\% do gênero masculino;

- maioria de solteiros (66\%), sem filhos (81\%), sendo que os casados representam somente $28 \%$ e alunos com filhos (um ou mais) somaram $19 \%$ dos respondentes;

- com relação ao local de trabalho, a maioria atua na iniciativa privada, sendo $42 \%$ em serviços, $23 \%$ na indústria e $19 \%$ no comércio; já $6 \%$ trabalham na administração pública ou no terceiro setor e $10 \%$ não estão trabalhando atualmente;

- dos 90\% que trabalham, 58\% exercem funções operacionais, 7\% atuam em cargos de supervisão, 15\% são gerentes de nível intermediário, 3\% estão locados na alta gerência e/ou diretoria, e 7\% são proprietários de empresas;

- com relação aos departamentos em que os entrevistados atuam nas organizações, onde trabalham, $42 \%$ atuam em setores administrativos, $16 \%$ em vendas, $12 \%$ em finanças, $4 \%$ em produção e 16\% atuam em outros departamentos (como RH, marketing, comércio exterior, qualidade, entre outros).

Esses resultados indicam que, apesar de iniciarem, em média, o ensino superior mais tarde, os indivíduos formam-se ainda jovens (aproximadamente 26 anos). Poucos casam-se ou têm filhos durante a graduação e permanecem em funções operacionais, apesar de a graduação gerar uma expectativa dos formados exercerem liderança no mercado de trabalho. Esses dados convergem com os estudos de Mantovani (1995) e Melo e Borges (2005), em que se discute que a graduação em administração atual não tem formado os líderes que o mercado de trabalho procura e muitos dos bacharéis continuam atuando nas mesmas funções de antes da graduação. 0 caminho utilizado para o crescimento profissional tem sido a realização de uma pós-graduação lato sensu.

Na continuidade das análises dos dados coletados, avaliou-se os resultados dos atributos encontrados na literatura. Os esforços foram destinados a encontrar os atributos de melhor e pior desempenho com relação à satisfação dos alunos com sua IES no que se refere a atributos específicos da instituição, seguindo-se da identificação dos atributos que mais contribuem para a satisfação destes alunos especificamente com relação aos atributos da IES. 


\section{IDENTIFICAÇÃO DOS ATRIBUTOS DE MELHOR DESEMPENHO NA AVALIAÇÃO DA SATISFAÇÃO DE ALUNOS COM SUA IES}

Na segunda parte da pesquisa, foram analisados dezoito atributos de satisfação de alunos relacionados a instituição de ensino (quadro 3). Para participar desse momento, o respondente deveria assinalar uma nota para cada atributo, que variava de 1 (que correspondia a "muito insatisfeito") a 7 (que correspondia a "muito satisfeito"). A questão S19 solicitava ao aluno que avaliasse todos os atributos ligados a IES de uma forma geral, também assinalando uma nota de 1 a 7, ou seja, sua satisfação geral com a IES.

Quadro 3: Atributos para a avaliação da satisfação de alunos quanto aos atributos da IES

\begin{tabular}{|c|c|}
\hline & ATRIBUTOS GERAIS DA INSTITUIÇĀO DE ENSINO \\
\hline S1 & Ambiente universitário, clima no campus, vida no campus \\
\hline S2 & Atendimento da equipe administrativa da IES \\
\hline S3 & Atendimento na secretaria e serviços de apoio na IES \\
\hline S4 & Atividades desportivas, culturais e associações de alunos \\
\hline S5 & Biblioteca e livraria universitária \\
\hline S6 & Construção das relações da IES com alunos \\
\hline S7 & Administração dos cursos \\
\hline S8 & Cortesia, amabilidade e competência dos funcionários da IES \\
\hline S9 & Disponibilidade de apoio social ao aluno e prestação de serviços sociais \\
\hline S10 & Gerenciamento e solução de reclamações de alunos \\
\hline S11 & Identificação de necessidades dos estudantes para novos serviços \\
\hline S12 & Imagem geral dos alunos quanto à IES \\
\hline S13 & Ligações da IES com o exterior, intercâmbios com o estrangeiro \\
\hline S14 & Preço, condições de pagamento e serviços financeiros \\
\hline S15 & Qualidade da IES percebida pelos alunos \\
\hline S16 & Confiança dos alunos na IES e seus funcionários \\
\hline S17 & Serviços, processos, modos de negociar e administração da IES \\
\hline S18 & Serviço educacional coerente com as necessidades dos alunos \\
\hline S19 & IES de uma forma geral \\
\hline
\end{tabular}


Tabela 1: Resultados das questões S1 a S19

\begin{tabular}{|c|c|c|c|c|c|}
\hline \multicolumn{6}{|c|}{ ESTATÍSTICAS BÁSICAS } \\
\hline Variável & S1 & S2 & S3 & S4 & S5 \\
\hline Média & 5,09187 & 4,40283 & 4,26855 & 3,95406 & 4,10954 \\
\hline Moda & $6(84$ casos $)$ & $4(78$ casos $)$ & $4(72$ casos $)$ & $4(79$ casos $)$ & $7(48$ casos $)$ \\
\hline Variância & 1,6511 & 1,87971 & 2,06947 & 2,122 & 4,16172 \\
\hline Desvio-padrão & 1,28495 & 1,37102 & 1,43856 & 1,45671 & 2,04003 \\
\hline Nota individual & 5,09 & 4,40 & 4,27 & 3,95 & 4,11 \\
\hline \multicolumn{6}{|c|}{ ESTATÍSTICAS BÁSICAS } \\
\hline Variável & S6 & S7 & S8 & S9 & S10 \\
\hline Média & 4,27915 & 4,54064 & 4,38869 & 4,23675 & 3,90459 \\
\hline Moda & $4(98$ casos $)$ & $4(84$ casos $)$ & $4(82$ casos $)$ & $5(81$ casos $)$ & $4(82$ casos $)$ \\
\hline Variância & 1,57073 & 1,7315 & 1,72072 & 1,74162 & 5,03696 \\
\hline Desvio-padrão & 1,25329 & 1,31586 & 1,31176 & 1,31971 & 2,24432 \\
\hline Nota individual & 4,28 & 4,54 & 4,39 & 4,24 & 3,90 \\
\hline \multicolumn{6}{|c|}{ ESTATÍSTICAS BÁSICAS } \\
\hline Variável & S11 & S12 & S13 & S14 & S15 \\
\hline Média & 4,18728 & 4,71731 & 3,61484 & 3,67845 & 4,57597 \\
\hline Moda & $4(96$ casos $)$ & $5(87$ casos $)$ & $4(74$ casos $)$ & $4(88$ casos $)$ & $4(87$ casos $)$ \\
\hline Variância & 1,71303 & 1,62903 & 2,57808 & 2,24021 & 1,40112 \\
\hline Desvio-padrão & 1,30883 & 1,27633 & 1,60564 & 1,49673 & 1,18369 \\
\hline Nota individual & 4,19 & 4,72 & 3,61 & 3,68 & 4,58 \\
\hline \multicolumn{6}{|c|}{ ESTATÍSTICAS BÁSICAS } \\
\hline Variável & S16 & S17 & S18 & S19 & \\
\hline Média & 4,50177 & 4,18021 & 4,44523 & 4,67845 & \\
\hline Moda & 5 (89 casos $)$ & $4(92$ casos $)$ & $4(94$ casos $)$ & $5(95$ casos $)$ & \\
\hline Variância & 1,64095 & 1,46741 & 1,25497 & 1,45297 & \\
\hline Desvio-padrão & 1,281 & 1,21137 & 1,12025 & 1,20539 & \\
\hline Nota individual & 4,50 & 4,18 & 4,45 & 4,68 & \\
\hline
\end{tabular}

Fonte: LHStat (2007)

Observando-se a tabela 1, pode-se constatar que o ambiente universitário, clima no campus, vida no campus (S1), obteve a maior nota individual, corroborando as pesquisas realizadas por Silva (2000), Walther (2000), Alves (2003), Navarro, Iglesias e Torres (2005). Os estudantes pesquisados afirmaram que um bom ambiente na IES mantém os alunos na mesma. Em segundo lugar, aparece a imagem que os alunos de uma forma geral têm da IES (S12), outro atributo que retém estudantes, conforme citam Alves (2003) e Navarro, Iglesias e Torres (2005). Em terceiro lugar, ficou o item qualidade da IES percebida pelos alunos (S15) (ALVES, 2003; OLAVARRIETA; OLIVA; MANZUR, 2003; GASTAL; LUCE, 2005; SANTOS; FERNANDES, 2005). Na seqüência, ficou a satisfação do aluno com a coordenação e organização dos cursos, administração dos cursos, competência dos administradores e coordenadores (S7), aspectos estudados anteriormente por Astin (2001), Alves (2003), Olavarrieta, Oliva e Manzur (2003), Walter, Tontini e Domingues (2005), e Navarro, Iglesias e Torres (2005). Estes quatro atributos receberam as maiores notas, representando maior satisfação dos alunos.

Constatou-se também que, dos 18 itens pesquisados, quatro deles ficaram abaixo da média 4 . Isso representa que a maior insatisfação dos alunos está:

a) nas atividades desportivas, culturais e associações de alunos (S4), atributo importante para Alves e Raposo (1999), Olavarrieta, Oliva e Manzur (2003) e Walter, Tontini e Domingues 
(2005);

b) no gerenciamento e solução de reclamações de alunos (S10) (ALVES; RAPOSO, 1999; SILVA, 2000, ALVES, 2003; SANTOS; FERNANDES, 2005);

c) nas ligações da IES com o exterior e intercâmbios com o estrangeiro (S13), avaliado anteriormente por Alves (1998), Alves e Raposo (1999), Alves (2003) e Walter, Tontini e Domingues (2005);

d) no preço, condições de pagamento e serviços financeiros (S14) (HAMPTON, 1993; ALVES, 2003; OLAVARRIETA; OLIVA; MANZUR, 2003; NAVARRO; IGLESIAS; TORRES, 2005; COLAUTO et al, 2005).

O penúltimo (S13) teve a pior nota entre todos os itens pesquisados. Estes quatro atributos merecem uma atenção especial por parte dos gestores das IES, pois indicam uma insatisfação dos alunos nas questões referidas pelos atributos.

Demais itens tiveram resultados positivos e pode-se considerar que eles contribuem, com mais ou menos força, para a satisfação dos alunos com a IES de seu curso de graduação em administração.

Fazendo-se uma análise da satisfação geral dos alunos, variável S19, pode-se considerar que o resultado é satisfatório. A nota obtida, 4,68, corresponde a $66,86 \%$ da nota máxima, ou seja, a satisfação dos alunos com sua IES no que se refere aos aspectos ligados a própria instituição é boa, visto que alunos que estão concluindo a graduação tem uma tendência a serem mais críticos do que alunos que estão começando o seu curso (OLAVARRIETA; OLIVA; MANZUR, 2003). Desta forma, pode-se considerar que os alunos estão satisfeitos com sua IES quanto aos fatores relacionados exclusivamente a instituição de ensino.

Continuando as análises, considerando-se que os dados foram validados e são confiáveis (alfa de Cronbach - 0, 9395), aplicou-se a regressão linear múltipla, onde buscou-se descobrir quanto representa cada item, do S1 ao S18, na composição da nota do item que avalia a satisfação geral dos alunos com sua IES (S19) (tabela 2).

Tabela 2 - Regressão linear múltipla dos itens S1 a S19

\begin{tabular}{c|c}
\hline Coef. correlação r & $+0,80952$ \\
\hline Coef. determinação r2 & 0,65532 \\
\hline Signific. ao nível de 5\% & Sim \\
\hline Erro padrão(resid.) & 0,731412 \\
\hline Observações & 283 \\
\hline
\end{tabular}




\begin{tabular}{|c|c|c|c|c|c|}
\hline \multicolumn{6}{|c|}{ COEFICIENTES } \\
\hline Var. & Descrição & Coeficien. & D. Padrão & Estat. $\mathrm{t}$ & Sign. \\
\hline Const. & & $+0,343048$ & 0,216037 & $+1,588$ & Não \\
\hline S1 & $\begin{array}{l}\text { Ambiente universitário, clima no campus, vida no } \\
\text { campus }\end{array}$ & $+0,0670948$ & 0,0466673 & $+1,438$ & Não \\
\hline $\mathrm{S} 2$ & Atendimento da equipe administrativa da IES & $+0,07132$ & 0,0587796 & $+1,213$ & Não \\
\hline S3 & $\begin{array}{l}\text { Atendimento na secretaria e serviços } \\
\text { de apoio na IES }\end{array}$ & $-0,0343985$ & 0,0561715 & $-0,612$ & Não \\
\hline S4 & $\begin{array}{l}\text { Atividades desportivas, culturais e } \\
\text { associações de alunos }\end{array}$ & $-0,0163679$ & 0,0425582 & $-0,385$ & Não \\
\hline S5 & Biblioteca e livraria universitária & $-0,0178375$ & 0,0292978 & $-0,609$ & Não \\
\hline S6 & Construção das relações da IES com alunos & $+0,143093$ & 0,0588332 & $+2,432$ & Sim \\
\hline S7 & Administração dos cursos & $+0,00970244$ & 0,05416 & $+0,179$ & Não \\
\hline S8 & $\begin{array}{l}\text { Cortesia, amabilidade e competência dos funcionários } \\
\text { da IES }\end{array}$ & $-0,0630724$ & 0,0586679 & $-1,075$ & Não \\
\hline S9 & $\begin{array}{l}\text { Disponibilidade de apoio social ao aluno e prestação de } \\
\text { serviços sociais }\end{array}$ & $-0,0659564$ & 0,0577956 & $-1,141$ & Não \\
\hline S10 & $\begin{array}{l}\text { Gerenciamento e solução de } \\
\text { reclamações de alunos }\end{array}$ & $-0,0364557$ & 0,023161 & $-1,574$ & Não \\
\hline S11 & $\begin{array}{l}\text { Identificação de necessidades dos estudantes para } \\
\text { novos serviços }\end{array}$ & $+0,144403$ & 0,0586973 & $+2,460$ & Sim \\
\hline $\mathrm{S} 12$ & Imagem geral dos alunos quanto a IES & $+0,164741$ & 0,0553441 & $+2,977$ & Sim \\
\hline S13 & $\begin{array}{l}\text { Ligações da IES com o exterior, intercâmbios com o } \\
\text { estrangeiro }\end{array}$ & $-0,0536468$ & 0,0418309 & $-1,282$ & Não \\
\hline $\mathrm{S} 14$ & Preço, condições de pagamento e serviços financeiros & $+0,0268833$ & 0,0390494 & $+0,688$ & Não \\
\hline $\mathrm{S} 15$ & Qualidade da IES percebida pelos alunos & $+0,134186$ & 0,0594288 & $+2,258$ & Sim \\
\hline S16 & Confiança dos alunos na IES e seus funcionários & $+0,114589$ & 0,0606606 & $+1,889$ & Não \\
\hline S17 & $\begin{array}{l}\text { Serviços, processos, modos de negociar e administração } \\
\text { da IES }\end{array}$ & $+0,119479$ & 0,0557124 & $+2,145$ & Sim \\
\hline S18 & $\begin{array}{l}\text { Serviço educacional coerente com as } \\
\text { necessidades dos alunos }\end{array}$ & $+0,245373$ & 0,0648656 & $+3,783$ & Sim \\
\hline S19 & IES de uma forma geral & & & & \\
\hline
\end{tabular}

t crítico (signif.) $=+/-1,96899$

Equação de regressão: S19 $=0,343048+0,0670948 * \mathrm{~S} 1+0,07132 * \mathrm{~S} 2-0,0343985 * \mathrm{~S} 3-0,0163679 * \mathrm{~S} 4-$ $0,0178375 * \mathrm{~S} 5+0,143093 * \mathrm{~S} 6+0,00970244 * \mathrm{~S} 7-0,0630724 * \mathrm{~S} 8-0,0659564 * \mathrm{~S} 9-0,0364557 * \mathrm{~S} 10$ $+0,144403 * \mathrm{~S} 11+0,164741 * \mathrm{~S} 12-0,0536468 * \mathrm{~S} 13+0,0268833 * \mathrm{~S} 14+0,134186 * \mathrm{~S} 15+0,114589 * \mathrm{~S} 16$ $+0,119479 * \mathrm{~S} 17+0,245373 * \mathrm{~S} 18$

Excluindo-se os atributos não significativos, constrói-se a nova equação de regressão somente com os atributos significativos:

Nova equação de regressão: S19 = 0,40392 +0,103171 * S6 +0,0694842* S11 +0,182497* S12 +0,1897* S15 $+0,141668 * \mathrm{~S} 17+0,274662 * \mathrm{~S} 18$ 
Análise Residual

Nível de signif. $=5 \%$; desvio-padrão residual $=0,731412$

(a) CASOS DISCREPANTES (OUTLIERS)

\begin{tabular}{c|c|c|c}
\hline CASO & RESÍDUOS $(\mathbf{Y})$ & DESVIOS $(\mathbf{Y})$ & FORÇA $(\mathbf{X})$ \\
\hline 149 & $+2,69673$ & 3,687 & 0,130 \\
\hline 156 & $-2,83811$ & 3,880 & 0,172 \\
\hline
\end{tabular}

(a) TESTE DE ALEATORIEDADE: $\mathrm{n}=283$; mediana $=-0,00387225$; repetições $=132 ; \mathrm{z}=-1,19311 ; \mathrm{z}$ crítico $=-1,64485$. Aceita a hipótese de aleatoriedade

(b) TESTE DE ADERÊNCIA KOLMOGOROV-SMIRNOV: D maior = 0,068; D critico = 0,080; Aceita hipótese de aderência à distribuição normal

(c) TESTE DE HOMOCEDASTICIDADE: t Levene = -2,33984; t crítico = -/+1,96844; Aceita a hipótese de homocedasticidade

Fonte: LHStat (2007)

Ao analisar a tabela 2, pode-se observar que os itens S6 (construção de relações da IES com seus alunos), S11 (identificação pela IES de necessidades dos estudantes no desenvolvimento de novos serviços), S12 (imagem geral dos alunos quanto a IES), S15 (qualidade da IES percebida pelos alunos da instituição), S17 (serviços, processos, modos de negociar e administração da IES) e S18 (serviço educacional coerente com as necessidades dos alunos) contribuem significativamente para a avaliação da satisfação dos alunos com os atributos de uma IES. Pode-se, desta forma, classificar os atributos segundo o modelo proposto por Tontini e Silveira (2005), adaptado para o serviço educacional:

- Atributos chave (alto desempenho declarado e alto desempenho calculado estatisticamente) - são os atributos mais representativos na satisfação, ou seja, sua melhoria aumenta a satisfação, e se não tiverem bom desempenho causam insatisfação:

- S18 (imagem dos alunos quanto a IES);

- Atributos amplificadores (baixo desempenho declarado e alto desempenho calculado estatisticamente) - atributos que não causam insatisfação quando ausentes, mas que aumentam a satisfação quando presentes:

- S12 (construção de relações da IES com seus alunos);

- S17 (identificação pela IES de necessidades dos estudantes no desenvolvimento de novos serviços);

- S21 (qualidade da IES percebida pelos alunos da instituição);

○ S23 (serviços, processos, modos de negociar e administração da IES);

○ S24 (serviço educacional coerente com as necessidades dos alunos);

- Atributos básicos (alto desempenho declarado e baixo desempenho calculado estatisticamente) - atributos que não causam satisfação quando presentes, mas que levam a grande insatisfação quando não atendem as expectativas:

- S7 (ambiente universitário, clima no campus, vida no campus); 
- Atributos secundários (baixo desempenho declarado e baixo desempenho calculado estatisticamente) - atributos que não geram nem satisfação nem insatisfação: demais atributos

Com os resultados obtidos, pode-se perceber que a imagem da IES entre os alunos é o principal atributo na formação da satisfação dos alunos. Ou seja, elevar a imagem da instituição entre os estudantes amplia a satisfação dos mesmos. Desta forma, a gestão eficaz de uma IES passa por preservar e melhorar a imagem da IES na visão dos alunos. Cuidados referentes a competência de corpo docente e colaboradores de outras áreas, relacionamento com o mercado, estruturas sempre em boas condições de uso, cumprimento de regras e normas, constroem uma imagem irrepreensível da IES perante aos estudantes, sendo este o principal fator de satisfação dos mesmos.

Para ampliar a satisfação dos estudantes, alguns atributos se mostraram importantes, como a construção de um relacionamento instituição-aluno, desenvolvimento de serviços na IES conforme as necessidades dos estudantes, preservar e aumentar a percepção dos alunos quanto a qualidade da IES, gestão eficaz da IES (orientada para os alunos e mercado), e um serviço educacional na medida adequada aos alunos. Estes atributos são fatores que podem elevar a satisfação dos estudantes com sua instituição. Quanto ao ambiente da IES, um ambiente positivo e favorável ao aprendizado e a troca de experiência é o mínimo que o aluno espera, configurando-se como sua expectativa inicial ao realizar seus estudos na instituição escolhida.

\section{CONCLUSÕES E RECOMENDAÇÕES}

Ao final deste estudo, conseguiu-se determinar que a satisfação dos alunos com sua IES, considerando apenas aspectos relacionados a própria instituição, é bem satisfatória, atingindo uma nota muito próxima a 7. Se for considerado que alunos formandos são mais críticos com seu curso e sua IES do que alunos que recém iniciaram o mesmo curso (OLAVARRIETA; OLIVA; MANZUR, 2003), pode-se afirmar que os estudantes da graduação em administração das IES de Joinville, SC, estão satisfeitos com a instituição de ensino que escolheram para realizar sua graduação, atendendo as expectativas dos alunos.

Estes alunos podem ser caracterizados por serem de maioria feminina, com idade média de 26 anos, solteiros, sem filhos, que já trabalham principalmente na iniciativa privada, exercem funções operacionais em setores administrativos das organizações onde atuam. Esta caracterização leva a algumas conclusões: uma predominância das mulheres na administração, algo já observado em outros estudos (MAINARDES; DESCHAMPS; DOMINGUES, 2006); apesar da maioria dos alunos já trabalharem, formam-se ainda jovens (26 anos); mesmo atuando em funções administrativas nas organizações onde trabalham, continuam exercendo funções operacionais, ou seja, esperava-se que formandos em administração já estivessem exercendo funções de liderança por terem realizado praticamente todo o curso de administração, mas o que se observou é que a graduação não garante o crescimento profissional dos indivíduos. Este resultado corrobora os estudos de Mantovani (1995) e Melo e Borges (2005).

Quanto a satisfação dos alunos dos cursos de graduação em administração das IES privadas de Joinville, SC com atributos relacionados exclusivamente a instituição de ensino, constatou-se que o ambiente universitário, clima no campus, vida no campus é o fator de maior satisfação entre os respondentes, informação esta importante para as IES envolvidas. Isto significa que, na visão dos alunos, as IES pesquisadas são bons lugares para os estudantes realizarem sua 
vida acadêmica, pois o ambiente é propício para o aprendizado e os alunos sentem-se bem quando estão na IES. 0 segundo item em satisfação foi a imagem que os alunos de uma forma geral têm da IES, outro resultado que favorece a atração e retenção de alunos nas IES pesquisadas. Pode-se concluir que o bom ambiente amplia a boa imagem da instituição entre os alunos. Também com bom resultado ficou o item qualidade da IES percebida pelos alunos. Os alunos mostraram-se satisfeitos quando a qualidade da instituição percebida por eles, ótimo indicador para as IES envolvidas no estudo. Outro atributo de bom desempenho foi a coordenação e organização dos cursos, administração dos cursos, competência dos administradores e coordenadores. Este resultado indica que os líderes mais próximos dos alunos satisfazem as expectativas dos mesmos. Cabe a gestão destas IES ficarem atentas a estes bons resultados, procurando assim manter, e se possível elevar, a satisfação dos alunos, mantendo estes atributos com bom desempenho.

Os resultados mais baixos, e que merecem atenção dos gestores das IES envolvidas na pesquisa referem-se a: atividades desportivas, culturais e associações de alunos; gerenciamento e solução de reclamações de alunos; ligações da IES com o exterior e intercâmbios com o estrangeiro; preço, condições de pagamento e serviços financeiros. Quanto ao pior resultado, as ligações da IES com o exterior e intercâmbios com o estrangeiro, este assunto merece atenção especial, pois na atual mundo globalizado, as IES precisam incentivar seus alunos a se relacionarem com o exterior, criando políticas e estabelecendo protocolos de cooperação para facilitar o acesso dos alunos a outros países. É uma ação que deve partir da IES, e tende a ser um grande fator de diferenciação entre as instituições de ensino do mercado. Além desta recomendação, estímulo as práticas desportivas, culturais, associações de alunos, pode ser o fator atrativo que falta nas IES atuais. Este item deve ser considerado pelos gestores destas instituições. Fatores preocupantes envolvem a gestão de reclamações dos alunos e os serviços financeiros das IES. Medidas administrativas na instituição, como processos mais ágeis e garantias de respostas, podem minimizar a insatisfação atual.

No que tange a formação da satisfação dos alunos, encontrou-se como atributo-chave a imagem dos alunos quanto a IES. Portanto, a satisfação dos alunos deve-se a imagem que a instituição consegue transmitir aos seus estudantes. 0 trabalho da gestão da IES consiste em acompanhar a imagem que os alunos têm da IES. Se esta for boa, gera e amplia a satisfação entre os estudantes. Destaque também para os fatores que podem aumentar (amplificar) a satisfação dos estudantes: desenvolver políticas que aprofundem as relações entre a IES e seus alunos; oferta de novos serviços focados nas necessidades dos alunos; avaliar periodicamente a qualidade percebida pelos alunos, efetuando as correções necessárias para evitar uma percepção de baixa qualidade; desenvolver políticas que deixem transparentes para os alunos os serviços, processos, modos de negociar e administração da instituição; permanentemente sejam oferecidos serviços educacionais que atendam as expectativas e necessidades dos alunos. Por fim, como fator básico, ou seja, o mínimo que o aluno espera, está a manutenção de um bom ambiente na IES. Este fator deverá ser alvo de acompanhamento constante dos gestores das IES.

Como limitações à pesquisa realizada, é importante ressaltar que envolveu somente uma cidade. A generalização para outras regiões requer cuidados quanto as características da cultura local. Outro fator limitante é que das cinco IES que oferecem a graduação em administração, duas IES ainda possuem cursos recentes e uma IES não autorizou a realização da pesquisa. É possível que no futuro, com uma pesquisa junto aos formandos das cinco IES, 
aconteça alguma alteração com relação aos resultados apresentados aqui.

Desta forma, a contribuição pretendida por este estudo remete-se a mensuração da satisfação dos alunos quanto a sua IES no que se refere a aspectos ligados exclusivamente a própria instituição. Os resultados apresentados podem ser importantes indicadores para os gestores e professores de outras IES no sentido de medirem a satisfação dos seus alunos quanto aos relevantes fatores elencados. Portanto, recomenda-se a replicação da mesma pesquisa apresentada aqui em outras regiões e IES para uma comparação dos resultados, possibilitando mapear a satisfação dos estudantes com suas IES.

\section{REFERÊNCIAS BIBLIOGRÁFICAS}

ABDULLAH, Firdaus. Measuring service quality in higher education: HEdPERF versus SERVPERF. Marketing Intelligence \& Planning, v. 24, n. 1, p. 31-47, 2006.

ALVES, Helena M. B. 0 marketing das instituições de ensino superior: o caso da Universidade da Beira Interior. 1999. 202f. Dissertação (Mestrado em Gestão) Departamento de Gestão e Economia, Universidade da Beira Interior, Covilhã, Portugal, 1998.

ALVES, Helena M. B. Uma abordagem de marketing à satisfação do aluno no ensino universitário público: índice, antecedentes e conseqüências. 2003, 286f. Tese (Doutorado em Gestão) - Departamento de Gestão e Economia, Universidade da Beira Interior, Covilhã, Portugal, 2003.

ALVES, Helena M. B.; RAPOSO, Mário. 0 marketing nas universidades: um estudo exploratório sobre a satisfação dos alunos como clientes no ensino superior. Revista Portuguesa de Marketing, ano 3, n. 8, p. 67-80, 1999.

ASTIN, Alan W. What matters in college? four critical years revisited. San Francisco: JosseyBass, 2001.

BARBETTA, Pedro A. Estatística aplicada às ciências sociais. Florianópolis: Ed. UFSC, 2003.

COLAUTO, Romualdo D.; MECCA, Marlei S.; MELO, Pedro A.; BEUREN, Ilse M. Variáveis determinantes da precificação baseada no valor: um estudo empírico em instituições de ensino superior privadas do estado de Santa Catarina. COLÓQUIO INTERNACIONAL SOBRE GESTIÓN UNIVERSITARIA EM AMÉRICA DEL SUR, 5, 2005. Mar del Plata. Anais... Mar Del Plata, V Colóquio Internacional sobre Gestión Universitária em América del Sur, 2005.

FRANKLIN, Kathy K; SHEMWELL, Donald. W. Disconfirmation theory: an approach to student satisfaction assessment in higher education. ANNUAL MEETING OF THE MID-SOUTH EDUCATIONAL RESEARCH ASSOCIATION CONFERENCE, 1995, Biloxi/MS. Anais... Biloxi/MS, Annual Meeting of the Mid-South Educational Research Association Conference, 1995.

GASTAL, Fernanda; LUCE, Fernando B.; A influência da satisfação e dos custos de mudança na lealdade do cliente. In: ENCONTRO NACIONAL DOS PROGRAMAS DE PÓS GRADUAÇÃO EM ADMINISTRAÇÃO, 29, 2005, Brasília. Anais... Brasília, XXIX ENANPAD, 2005.

HAIR Jr., Joseph F.; BABIN, Barry; MONEY, Arthur H.; SAMOUEL, Phillip. Fundamentos e métodos de pesquisa em administração. Porto Alegre: Bookman, 2005.

HAMPTON, Gary M. Gap analysis of college student satisfaction as a measure of professional 
service quality. Journal of Professional Services Marketing, v. 9, n. 1, p. 369-380, 1993.

INEP. Instituto Nacional de Estudos e Pesquisas Educacionais. 2007. Disponível em <http://www.inep.gov.br/>.

LANZER, Letícia de S. Estratégias de marketing de relacionamento para instituições de ensino superior: um estudo de caso na Universidade do Sul de Santa Catarina. 2004, 182f. Dissertação (Mestrado em Engenharia da Produção) - Programa de Pós-Graduação em Engenharia de Produção, Departamento de Engenharia de Produção e Sistemas, Universidade Federal de Santa Catarina, Florianópolis, 2004.

MAINARDES, Emerson W. Atração e retenção de alunos em cursos de graduação em administração das instituições particulares de ensino superior de Joinville, SC. 2007. 332f. Dissertação (Programa de Pós-Graduação em Administração) - Centro de Ciências Sociais Aplicadas, Universidade Regional de Blumenau, Blumenau, 2007.

MAINARDES, Emerson W.; DESCHAMPS, Marcelo, DOMINGUES, Maria J. C. de S. As expectativas de graduandos em administração quanto a pós-graduação na modalidade especialização. ENCONTRO NACIONAL DE CURSOS DE GRADUAÇÃO EM ADMINISTRAÇÃO, 17, 2006, São Luís. Anais... São Luís, XVII ENANGRAD, 2006.

MANTOVANI, Neodir O. Avaliação do ensino de administração na perspectiva de egressos e dirigentes de empresas. ENCONTRO NACIONAL DE CURSOS DE GRADUAÇÃO EM ADMINISTRAÇÃO, 6, 1995, Natal. Anais... Natal, VI ENANGRAD, 1995.

MAVONDO, Felix T.; CHIMHANZI, Jacqueline; STEWART, Jillian. Learning orientation and market orientation: relationship with innovation, human resource practices and performance. European Journal of Marketing, v. 39, n. 11/12, p. 1235-1263, 2005.

MELO, Simone L. de; BORGES, Lívia de O. Transição universidade-mercado de trabalho na ótica do jovem. ENCONTRO NACIONAL DOS PROGRAMAS DE PÓS GRADUAÇÃO EM ADMINISTRAÇÃO, 29, 2005, Brasília. Anais... Brasília, XXIX ENANPAD, 2005.

NAVARRO, Mercedes M.; IGLESIAS, Marta P.; TORRES, Pilar R. A new management element for universities: satisfaction with the offered courses. International Journal of Educational Management, v. 19, n. 6, p. 505-526, 2005.

OLAVARRIETA, Sergio; OLIVA, Ismael; MANZUR, Enrique. Medición de la calidad de servicios en la educación superior de negocios en Chile: un estudio comparativo de modelos SERVPERF - SERVQUAL. CLADEA, 38, 2003, Lima/Peru. Anais... Lima/Peru, XXXVIII CLADEA, 2003.

PALACIO, Asunción B.; MENESES, Gonzalo D.; PÉREZ, Pedro J. P. The configuration of the university image and its relationship with the satisfaction of students. Journal of Educational Administration, v. 40, n. 5, p. 486-505, 2002.

PLANALTO, Palácio do. Lei número 9.394, de 20 de dezembro de 1996. Presidência da República, Casa Civil, Subchefia para Assuntos Jurídicos. Disponível em <http://www.planalto.gov.br/CCNILI_03/leias/L9394.htm>.

REINERT, José N.; REINERT, Clio. Estudante não é cliente: é parceiro. ENCONTRO NACIONAL DOS PROGRAMAS DE PÓS GRADUAÇÃO EM ADMINISTRAÇÃO, 29, 2005, 
Brasília. Anais... Brasília, XXIX ENANPAD, 2005.

ROWLEY, Jennifer. Information marketing: seven questions. Library Management, v. 24, $\mathrm{n}$. 1/2, p. 13-19, 2003.

SANTOS, Cristiane P. dos; FERNANDES, Daniel V. D. H. A recuperação de serviços como ferramenta de relacionamento: seu impacto na confiança e lealdade dos cliente. ENCONTRO NACIONAL DOS PROGRAMAS DE PÓS GRADUAÇÃO EM ADMINISTRAÇÃO, 29, 2005, Brasília. Anais... Brasília, XXIX ENANPAD, 2005.

SEEMAN, Elaine D.; O'HARA, Margaret. Customer relationship management in higher education using information systems to improve the student-school relationship. CampusWide Information Systems, v. 23, n. 1, p. 24-34, 2006.

SILVA, Ana C. B. Elementos para desenvolver um projeto próprio de avaliação institucional. Anais do Seminário Gestão de IES: da teoria à prática. Fundação Nacional de Desenvolvimento do Ensino Superior Particular. Brasília: Funadesp, 2000. 148 p.

SILVA, Walmir R. da; BRANDÃO JUNIOR, Roberto D.; SOUTO, Jackson V.; SILVA JUNIOR, Nelson A. da. Escolha do curso de administração: uma análise comparativa entre uma instituição pública e uma instituição privada. ENCONTRO NACIONAL DOS PROGRAMAS DE PÓS GRADUAÇÃO EM ADMINISTRAÇÃO, 29, 2005, Brasília. Anais... Brasília, XXIX ENANPAD, 2005.

TONTINI, Gerson; SILVEIRA, Amélia. Identificação de atributos críticos de sucesso em produtos e serviços: uma alternativa a análise de importância X desempenho. BALAS 2005 ANNUAL CONFERENCE, 2005, Madrid/Espanha. Anais... Madrid/Espanha, Balas 2005, 2005.

WALTER, Silvana A.; TONTINI, Gerson; DOMINGUES, Maria J. C. S. Identificando oportunidades de melhoria em um curso superior através da análise da satisfação dos alunos. ENCONTRO NACIONAL DOS PROGRAMAS DE PÓS GRADUAÇÃO EM ADMINISTRAÇÃO, 29, 2005, Brasília. Anais... Brasília, XXIX ENANPAD, 2005.

WALTHER, Edgar. The relationships between student satisfaction and student retention in higher education. 2000, 287f. Dissertação (Mestrado em Administração) - Faculty of The Graduate School, The University of North Carolina, Greensboro, 2000. 